\title{
Rádio educativa e mídias sociais digitais: perspectivas e desafios da fanpage da Rádio Unesp FM
}

Educational radio and digital social media: perspectives and challenges of the Radio Unesp FM fanpage

Radio educativa y medios sociales digitales:

perspectivas y desafíos de la fanpage de la Radio Unesp FM

Maximiliano Martin Vicente

- Doutor em História Social e livre-docente em História do Brasil pela Universidade de São Paulo

- Mestrado em História pela Universidade Estadual Paulista (Unesp-Bauru)

- Graduado em História pela Universidade do Sagrado Coração (USC), de Bauru

- Professor da Unesp-Bauru, nos cursos de Comunicação Social e no programa de Pós-Graduação em Comunicação Midiática

- Organizador e co-oorganizador de uma série de coletâneas

- E-mail: maxvicente@uol.com.br

Christiane Delmondes Versuti

- Mestre em Comunicação na Universidade Estadual Paulista (Unesp-Bauru)

- Cursou um semestre de Ciências da Comunicação na Universidade do Minho, Portugal

- - Graduada em Comunicação Social - Relações Públicas pela mesma instituição

- Desenvolveu o projeto de iniciação científica "O papel do relações-públicas e uma comunicação multidisciplinar na sedimentação da imagem organizacional de uma rádio educativa: Rádio Unesp FM"

- E-mail: christianedversuti@hotmail.com 


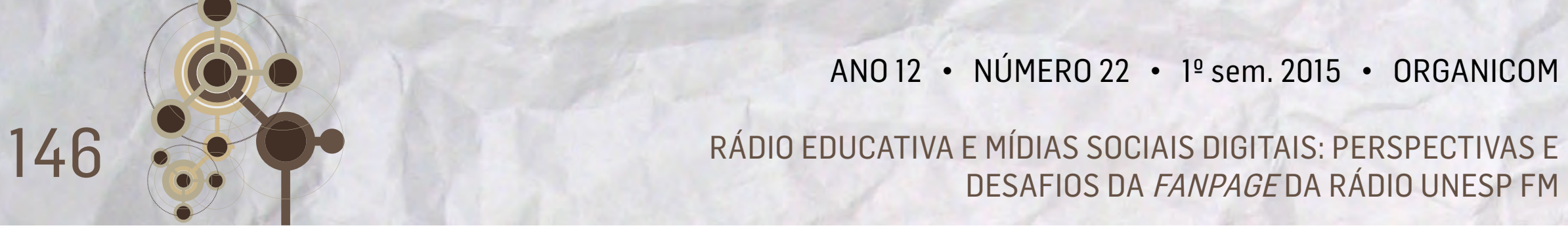

\section{Resumo}

O artigo pretende discutir a utilização da fanpage pela Rádio Unesp FM, rádio pública de caráter cultural e educativo. Para tal, foram empreendidas leituras sobre rádios educativas, rádio e internet e organizações nas mídias sociais, e realizada análise das publicações de janeiro a junho de 2014, utilizando dados gerados pelo Facebook Insights. Espera-se que trabalho aponte caminhos para aprimorar o uso dessa plataforma não só pela Rádio Unesp, mas também por outras emissoras educativas, para que obtenham êxito em seus objetivos de propagar conteúdos caros à educação, cultura e cidadania.

\section{PALAVRAS-CHAVE: RÁDIO EDUCATIVA • MÍDIAS SOCIAIS DIGITAIS • CONVERGÊNCIA •INTERATIVIDADE • COMUNICAÇÃO ORGANIZACIONAL.}

\section{Abstract}

The article discusses the use of the fanpage by Radio Unesp FM, a public radio station (of the São Paulo State University) with cultural and educational characteristics. To achieve this readings were obtained from educational radio stations, radio and Internet and organizations in the social media, and an analysis was conducted of the broadcasts from January to June 2014 , using data generated by Facebook Insights. It is expected that this work will show ways to improve the use of this platform not only for Radio Unesp, but also by other educational stations, so as to obtain success in their goals of disseminating content related to education, culture and citizenship.

\section{KEYWORDS: EDUCATIONAL RADIO • DIGITAL SOCIAL MEDIA • CONVERGENCE •INTERACTIVITY • ORGANIZATIONAL COMMUNICATION.}

\section{Resumen}

El artículo pretende discutir el uso de la fanpage por la Radio Unesp FM, radio pública de carácter cultural y educativo. Para esto se realizaron lecturas sobre radios educativas, radio e internet y organizaciones en los medios sociales, y se hicieron análisis de las publicaciones desde enero a junio de 2014, a partir de datos generados por Facebook Insights. Se espera que este trabajo apunte maneras de mejorar el uso de esta plataforma no sólo para la Radio Unesp, como también para otras emisoras educativas, para que obtengan éxito en sus metas de propagar contenidos relacionados con la educación, la cultura y la ciudadanía. 


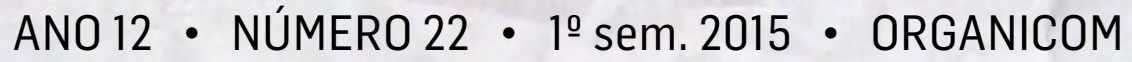 \\ RÁDIO EDUCATIVA E MÍDIAS SOCIAIS DIGITAIS: PERSPECTIVAS E DESAFIOS DA FANPAGE DA RÁDIO UNESP FM}

categoria das rádios educativas não tem fins lucrativos e, como descrito por Luiz Ferrareto (2001, p. 49), sua
manutenção é garantida pela União, por governos estaduais ou municipais, fundações constituídas com essa
finalidade e universidades. Em relação à legislação sobre rádios educativas, Ivete Roldão coloca duas questões essenciais: a política de concessões e o conteúdo da programação. Em função dos dois critérios, a autora as conceitua da seguinte maneira: "Rádios consideradas educativas são concessões destinadas a universidades, fundações ligadas a empresas privadas, governos estaduais ou municipais ou mesmo diretamente a prefeituras, ou seja, às emissoras públicas ou estatais" (Roldão, 2006, p. 1).

Sobre os vínculos institucionais dessas emissoras, Marlene Blois (2003, p. 11) aponta que tais vínculos podem ser firmados em relação a órgãos nacionais ou locais, como entidades da iniciativa privada, desde que seus objetivos estejam voltados para ações que privilegiem a cultura e a educação, nos seus aspectos formativo e informativo. As rádios educativas ligadas a instituições e universidades têm o papel de contribuir para a formação dos alunos; divulgar o conhecimento científico; contribuir para a democratização da comunicação, estendendo as atividades da universidade pública para a sociedade e reconhecendo a pluralidade de culturas, dando espaço a elas em sua programação, principalmente àquelas que são ignoradas pelas emissoras comerciais.

Os conteúdos veiculados pelas emissoras comerciais não necessariamente promovem a reflexão e a diversidade cultural, pois muitas vezes o que vemos é apenas a reprodução de uma cultura massificada e mercantilizada. Segundo Roldão (2006, p. 1), nessas emissoras o interesse mercadológico ocupa cada vez mais espaço na programação e, dessa forma, o ouvinte é tratado como consumidor em potencial e não como cidadão. Escreve, a propósito, Paula Cordeiro (2005, p. 9):

Dado o facto de a rádio privada ter fortes preocupações com a rentabilidade e optar por oferecer um produto de entretenimento puro, sem grandes preocupações artísticas ou ao nível de informação de atualidades, são os sistemas alternativos de comunicação radiofônica, como o Serviço Público e as rádios universitárias que têm vindo a desenvolver programações que fogem ao ritmo da comunicação radiofônica comercial, apresentando elementos na sua programação de caráter experimental e de formação de novos valores, contribuindo para o debate de ideias e fomento da aproximação entre as rádios e os ouvintes.

Assim, como alternativa às rádios privadas, notadamente com programação voltada apenas à rentabilidade, Paula Cordeiro (2005) aponta o Serviço Público e as rádios universitárias como alternativa possível, pois a programação dessas últimas possui caráter experimental, que apresenta novos valores e ideias, maior preocupação em relação à arte e informação, e a busca pela aproximação entre emissoras e audiência. Nesse sentido, Marlene Blois (2003) considera a programação de uma emissora educativa como a grande marca que a difere de uma emissora comercial. Para a autora,

as formas utilizadas para concretizar seus propósitos e chegar aos ouvintes vão desde as mais didáticas - como cursos e séries institucionais - até realizações menos formais, mas não menos educativas, como o radiojornalismo, séries e spots culturais ou de utilidade pública, seleç̃̃es musicais e prestação de serviços à comunidade, propostas descompromissadas de interesses comerciais e modismos fabricados. É a educação aberta e continuada se realizando em linguagem coloquial e com forte apelo afetivo (Blois, 2003, p. 10).

Assim, é dever de uma rádio educativa valorizar sua própria cultura, dar espaços às diversas formas de expressões culturais existentes e veicular conteúdos relevantes para o desenvolvimento do cidadão.

A linha editorial de uma emissora educativa tem como base o tripé informação/prestação de serviços, programas culturais/ educativos e música, devendo os conteúdos educativos estar dispersos durante toda a sua programação e não concentrados 


\section{ANO 12 • NÚMERO $22 \cdot 1^{10}$ sem. 2015 - ORGANICOM \\ RÁDIO EDUCATIVA E MÍDIAS SOCIAIS DIGITAIS: PERSPECTIVAS E DESAFIOS DA FANPAGE DA RÁDIO UNESP FM}

em horários especiais (Roldão, 2006). A programação musical também se torna educativa quando são veiculadas canções que resgatem a cultura local, por meio das letras ou por meio de grupos e artistas da região.'

Expostas essas características, pretende-se apontar o uso da internet e de plataformas de interatividade como forma de ampliar o impacto da programação dessas rádios que, diferentemente das rádios comerciais, prezam pela qualidade da informação, da promoção da cidadania e da diversidade cultural.

Visto isso, é preciso ficar atento às inovações tecnológicas, perceber como elas afetam a rádio e buscar alternativas de como podem ser utilizadas de forma complementar. Configura-se assim um desafio à radiodifusão educativa: a utilização de outros meios para reforçar e enriquecer as mensagens de suas emissões.

\section{RÁDIO NA INTERNET}

A união do rádio com a internet ocorreu por volta da década de 1990, com o surgimento das primeiras emissoras "www" com o foco de levar para a rede sua presença institucional. Nessa primeira fase, procurava-se levar a "imagem" empresarial, disponibilizando conteúdos sobre o perfil da emissora; já numa segunda fase, a preocupação passou a ser levar algo a mais, afim de atrair os "ciberouvintes".

Estabelecendo sua presença na rede, o rádio passa a ganhar outra temporalidade, pois torna-se possível disponibilizar arquivos para que os ouvintes possam conferir os programas em outros horários. "A rádio passa a oferecer serviços que unem ao som elementos escritos e visuais e junta-se a outros media para estar presente e responder às solicitações do consumidor multimídia" (Cordeiro, 2004, p. 2).

As novas demandas apresentadas por esse consumidor multimídia não poderiam ser supridas pelo rádio tradicional. Com a utilização da internet como suporte de apoio isso se faz possível, agregando à programação radiofônica elementos audiovisuais e hiperlinks. Assim, são quebradas as barreiras temporais e geográficas, transformando também a noção de espaço de armazenamento.

\footnotetext{
Na internet, a rádio reúne música, informação e publicidade, em paralelo com outros componentes como animações, imagens estáticas ou em movimento. Os novos suportes permitem a introdução de componentes (gráficos, tabelas, fotografias, textos escritos, imagens de vídeo) que vêm complementar a informação disponibilizada pelo meio. Este aspecto vai obrigar a uma adaptação a esta nova forma de comunicar, com recursos que vão permitir produzir uma mensagem tão completa quanto possível (Cordeiro, 2004, p. 4).
}

A principal diferença entre a rádio do passado e a rádio da atualidade é a busca da interatividade, pois muitos procuram entretenimento, outras maneiras de aprimorar sua formação, mas, sobretudo, todos desejam participar. Assim, como destacado por Roseane Andrelo e Maria Teresa Kerbauy (2009, p. 163), "utilizar o suporte internet é outra maneira de garantir a participação dos ouvintes". Para Paula Cordeiro (2004, p. 5), "o estilo multimediático agora utilizado recorre a quase todos os recursos da rede, como a interatividade, as hiperligações, com a imagem, personalização e atualização constante, aspectos que não encontramos no formato tradicional da rádio".

Surgem então, novas formas discursivas na produção radiofônica, pois existe a possibilidade da "combinação de elementos de linguagens diferentes, menos singular, contudo, mais rica, por via da utilização multimédia na construção da sua 


\section{ANO 12 • NÚMERO $22 \cdot 1^{10}$ sem. 2015 - ORGANICOM \\ RÁDIO EDUCATIVA E MÍDIAS SOCIAIS DIGITAIS: PERSPECTIVAS E DESAFIOS DA FANPAGE DA RÁDIO UNESP FM}

mensagem" (Cordeiro, 2004, p. 6). Na web, o rádio ganha "uma nova perspectiva de aproveitamento, por meio da ampliação da linguagem para além de signos sonoros, para signos de outras naturezas, como os signos visuais" (VELHO, 2005, p. 2).

Mariano Cebrián Herreros (2011) aponta que o rádio não deve ser compreendido como uma ilha, mas como um meio integrante de um ecossistema comunicativo mutante, complexo e dinâmico, que agrupa diferentes plataformas comunicativas que dialogam entre si.

Essa realidade exige deles uma revisão nos seus conceitos, na sua caracterização e em alguns casos até em seu papel na sociedade. Não se trata da morte de um meio devido ao fortalecimento de outro, mas de uma adequação, do desenvolvimento do ecossistema comunicacional de maneira integrada, compreendendo o contexto da cultura da convergência (Lopez; Quadros, 2014, 178).

Com a tecnologia, o consumo de rádio também não se dá apenas através do aparelho radiofônico, mas também por variados tipos de dispositivos móveis como notebooks, tablets, celulares e outros que tenham conexão com a internet e saída de áudio. Todos esses dispositivos permitem a interação com o usuário. Dessa forma, pode-se dizer que a as novas tecnologias tornaram o rádio ainda mais participativo. "Face à convergência dos meios de comunicação social num só suporte, a rádio pode representar um dos diversos canais deste novo meio de comunicação, que se evidencia pelo estímulo à participação dos seus utilizadores e deita por terra a passividade da audiência" (Cordeiro, 2004, p. 5).

Com a disponibilidade de novos mecanismos trazidos pela rede ao rádio, é necessário gerar e readaptar espaços físicos e virtuais das emissoras, com equipes capacitadas para atuação nos ambientes off-line e on-line, atentando para novos padrões comunicacionais de participação e interatividade. Tais características podem ser desenvolvidas no ambiente das mídias sociais digitais. Assim, apresenta-se como possibilidade a utilização do Facebook e a criação de uma fanpage institucional para as rádios, atentando aqui para as rádios educativas.

\section{ORGANIZAÇÕES NAS MÍDIAS SOCIAIS}

Saindo da noção de rádios educativas na internet e partindo para uma visão organizacional, é possível afirmar que as organizações estão passando por um processo de adaptação no ambiente das redes sociais e também de aprendizado para perceberem a melhor maneira para trabalhar com elas.

Segundo Carolina Terra (2008, p. 31), a comunicação digital é "segmentada, de relevância para o usuário, bidirecional, interativa, que permite a participação e a construção coletiva, direta, ágil, de rápida disseminação (capacidade viral) e que pode ser gerada pelo consumidor". Assim, fazer uso das mídias sociais possibilita o estabelecimento de relacionamentos com a audiência, uma vez que sua opinião pode ser ouvida e levada em conta.

De acordo com Daniella Cornachione (2010), as organizações já entenderam que as redes sociais on-line podem auxiliar 0 fortalecimento da marca, da imagem e na conquista de mais clientes. Contudo, para a maioria, ainda é um grande desafio saber como utilizá-las de maneira apropriada.

Em 2010, pesquisa aplicada pelo Instituto Brasileiro de Inteligência de Mercado (Ibramerc, 2010) demonstrou que 65\% das empresas brasileiras já estão inseridas nas redes sociais, mas uma parcela muito pequena, de apenas $7 \%$, considera sua 


\section{ANO $12 \cdot$ NÚMERO $22 \cdot 1^{10}$ sem. $2015 \cdot$ ORGANICOM \\ RÁDIO EDUCATIVA E MÍDIAS SOCIAIS DIGITAIS: PERSPECTIVAS E DESAFIOS DA FANPAGE DA RÁDIO UNESP FM}

utilização indispensável. E 47,9 \% indicaram tais meios como uma iniciativa desejável. De maneira geral, o estudo revelou uma opinião favorável das empresas em ralação às redes sociais. Contudo, quase metade delas utiliza esses meios de maneira equivocada, o que pode prejudicar a marca e criar uma imagem negativa sobre as organizações.

O contato direto e aberto aos públicos pode causar medo em algumas organizações, mas esse não deve ser o caso de uma rádio pública e educativa, uma vez que sua principal função é comunicar. Para Cornachione (2010), muitas instituições perdem oportunidades ao não incluí-las em suas estratégias; contudo, muitas das instituições que se aventuram pelas mídias sociais não sabem como utilizá-las de modo correto.

Então, como fazer? Não existe uma receita de como utilizar as redes sociais, mas existem parâmetros básicos que podem servir como base. De acordo com Diego Ivo (2010), sobressaem as empresas que procuram lidar e se relacionar com seu público. E, como afirma Wilson da Costa Bueno (2003, p. 60),

o relacionamento com os públicos de interesse deve pautar-se, agora, por agilidade e interatividade, e os comunicadores organizacionais devem ter a capacidade de estabelecer estratégias que levem em conta a potencialidade da internet. As organizações ainda encontram dificuldades para se adaptar às novas mídias, com formatos e linguagens ainda insuficientemente explorados, mas, paulatinamente, vão descobrindo formas de conviver com elas.

A internet e as mídias sociais já fazem parte da vida das pessoas, e cada vez mais são criadas novas maneiras de usá-las. 0 volume de usuários presentes em mídias sociais no Brasil continua crescendo, e as organizações que não se adequarem a essa realidade perderão a oportunidade de ampliar e fidelizar sua clientela, o que para uma emissora de rádio (como a Rádio Unesp), seria o mesmo que perder a oportunidade de ampliar e fidelizar sua audiência.

Em relação ao conteúdo, tudo o que é postado deve ter um motivo e ser relevante, seja para informar, entreter, buscar opiniões, criar humor, causar emoção, promover interação etc. E elementos como cores, imagens, textos, links, áudios e vídeos devem estar de acordo com os objetos específicos da organização.

Os meios mudaram, se tornaram conversacionais, dialógicos, permitindo a cocriação e a colaboração entre pessoas e as expressões individuais. A exposição exacerbada não se aplica apenas às marcas, organizações ou celebridades, mas também às pessoas comuns, na era dos "megafones digitais". Frente a essa realidade, é necessário saber lidar com o grande volume de informação, audiências, críticas, boatos e situações.

Para atuar nas mídias sociais (especificamente no Facebook, por meio da fanpage), a Rádio Unesp precisa compreender que os protagonistas nessas mídias são as pessoas comuns. Usuários que querem conteúdo de qualidade, informação, educação, cultura, mas, estando nas mídias sociais, querem também diálogo e relacionamento. Se eles curtiram a fanpage, é porque têm interesse em receber conteúdos complementares e diferenciados, com a possibilidade de interagir com a emissora e fazer parte de sua produção.

Como diz Daniella Cornachione (2010), não há uma estimativa exata do valor das ações de marketing nas mídias sociais, mas essa é uma maneira de alcançar milhões de pessoas e criar uma relação lúdica com elas. Porém, é preciso que haja uma equipe capacitada para criar tal relação e conduzi-la de acordo com os objetivos da organização. No caso da Rádio Unesp FM, seus objetivos seriam levar informação, educação e cultura para seu público. Dessa forma, esse deve ser o norte para os gestores de sua fanpage, para que tenha êxito em sua empreitada nas mídias sociais digitais. 


\section{CONTEXTUALIZAÇÃO SOBRE A RÁDIO UNESP FM}

Antes de iniciar o tópico com as análises dos dados obtidos através da pesquisa sobre fanpage da Rádio Unesp FM, é importante realizar uma contextualização acerca de sua história, seu perfil e sua função social como rádio pública de caráter cultural e educativo.

A Unesp FM está sediada no campus da Unesp Bauru (SP) e realizou sua primeira transmissão em 13 de maio de 1991. Sintonizada na frequência de $105,7 \mathrm{MHz}$, a emissora trabalha com potência de transmissão de 3.000 watts e atende um raio de 100 km, o que permite atender a cidade de Bauru e a região

É uma emissora pública de caráter cultural e educativo, com uma grade de programação diversificada que oferece aos ouvintes, cultura, educação, prestação de serviços, informação e programas temáticos de diferentes áreas.

A programação musical contempla vários gêneros como jazz, rock, blues, erudito, orquestras, newage, pope, principalmente, vertentes da música popular brasileira, como choro, samba, música instrumental, clássicos e novidades da MPB.

Suas produções jornalísticas têm enfoque no conceito do jornalismo público, e ela busca relatar fatos do cotidiano, oferecendo reflexão sobre notícias impactantes com a participação de pesquisadores, especialistas e autoridades nas entrevistas diárias (geralmente ao vivo), possibilitando a participação do ouvinte.

A emissora também conta com a colaboração de docentes e pesquisadores da Universidade Estadual Paulista como fontes de informação na prestação de serviços com aprofundamento das informações e também divulga pesquisas científicas e eventos acadêmicos.

Além disso, a Rádio Unespé aberta aos projetos de docentes e alunos dos cursos de graduação da universidade, principalmente os de Comunicação Social, contribuindo para a aplicação prática dos conhecimentos adquiridos em sala de aula, através da realização de pesquisas e desenvolvimento de projetos de extensão.

Dentre os vários projetos de extensão e pesquisas realizadas acerca da Rádio Unesp FM pode-se citar o projeto de iniciação científica $A$ pesquisa qualitativa e o papel do relações públicas na sedimentação da imagem organizacional de uma rádio educativa: Rádio Unesp Bauru, concluído em 2012 por Christiane Versuti, e duas dissertações de mestrado: Interação comunitária: o cidadão em sintonia radiofônica, defendida em 2013 pela pesquisadora Aline Meneguini, e A representação caipira na Unesp FM, de autoria de Wellington Leite, defendida também em 2013.

Terminada a contextualização, será possível visualizar de maneira mais abrangente os dados colhidos, bem como a importância de trabalhar de forma mais eficiente a presença emissora nas mídias sociais digitais, a fim de que seja ampliado o impacto cultural de sua programação.

\section{PANORAMA GERAL DE JANEIRO A JUNHO DE 2014}

Apresentadas as questões sobre rádios educativas, rádio e internet e organizações nas mídias sociais, bem como a contextualização sobre a Unesp FM, será mostrado a seguir um quadro geral sobre as atividades observadas na fanpage 
de janeiro a junho de 2014, com a utilização de gráficos gerados a partir de dados disponíveis no Facebook Insights. Para a criação das categorias de análise dos temas abordados, nos inspiramos na análise de conteúdo de Laurence Bardin (1977).

Através desses gráficos pretende-se avaliar como a plataforma está sendo utilizada pela Rádio Unesp e o que pode ser aprimorado para tornar esse canal de comunicação eficaz no diálogo com os ouvintes e na propagação de conteúdos relativos à educação, cultura e cidadania, objetivo principal dessa organização.

Gráfico 1 - Publicações divididas por temática, de janeiro a junho de 2014.

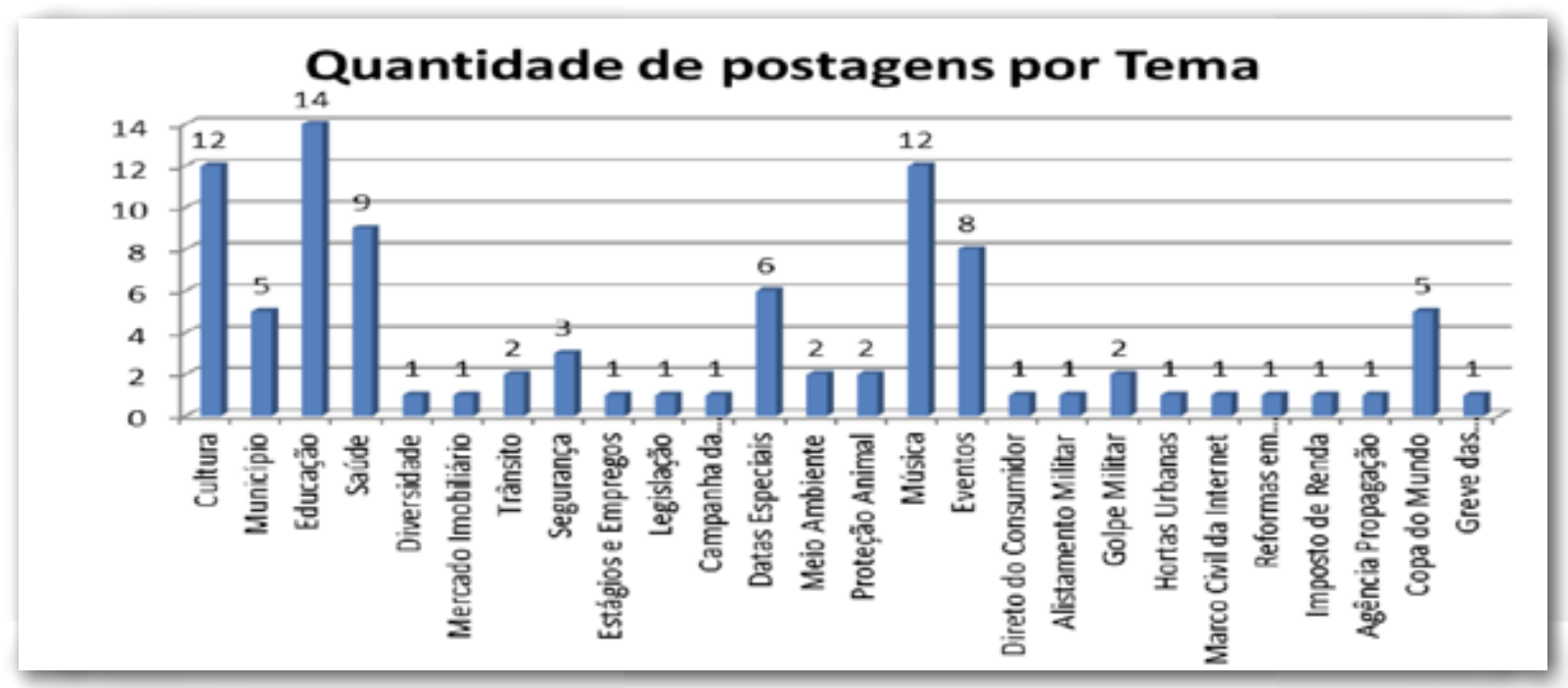

Fonte: Elaborado pelos autores.

Os temas mais publicados na fanpage no período de análise foram Educação e Música, Cultura e Saúde, seguidos pelos temas Eventos, Datas Especiais, Município e Copa do Mundo. As outras temáticas abordadas se relacionam com Segurança, Trânsito; Meio Ambiente; Proteção Animal; Golpe Militar, seguidas pelas temáticas Diversidade, Mercado Imobiliário, Estágios e Empregos, Legislação, Campanha da Fraternidade, Direito do Consumidor, Alistamento Militar, Hortas Urbanas, Reformas em Habitação, Imposto de Renda, Agência Propagação e Greve das Universidades.

Como se pode notar, de forma geral, as temáticas abordadas são coerentes com a função e os objetivos da emissora, como rádio pública e educativa, cuja programação é pautada em cultura, educação e cidadania. Destacaram-se postagens sobre Educação, Música e Cultura, mesclando temas relativos à realidade local, assuntos de interesse público e acontecimentos referentes à vida universitária.

Gráfico 2 - Curtidas por tema, de janeiro a junho de 2014.

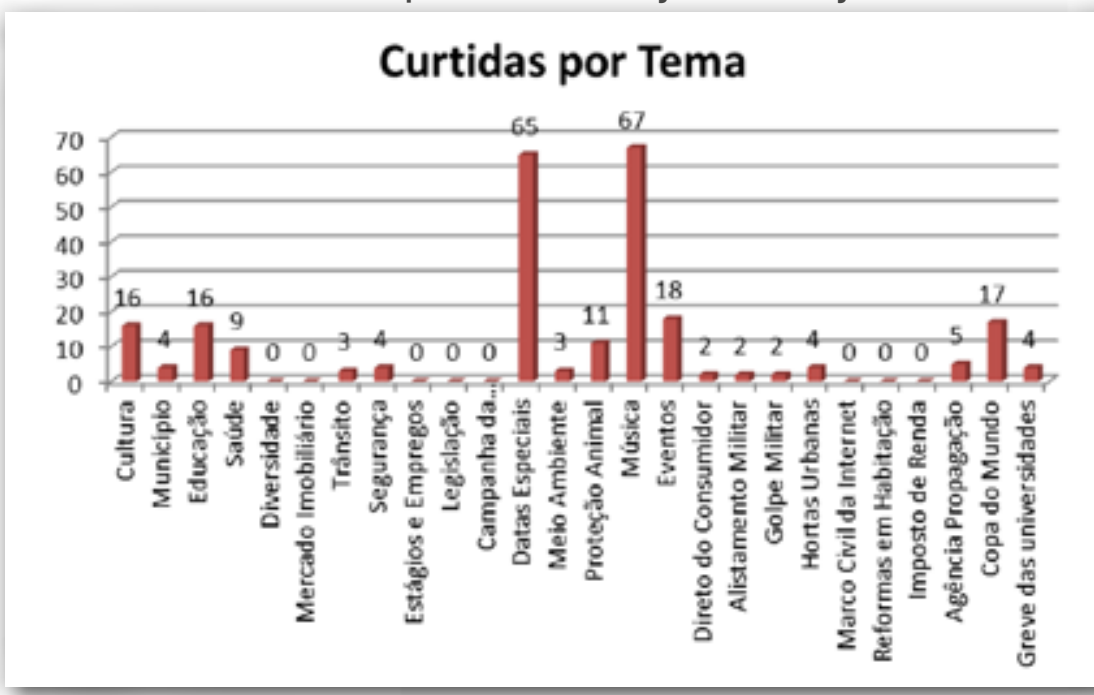

Fonte: Elaborado pelos autores. 


\section{ANO $12 \cdot$ NÚMERO $22 \cdot 1^{10}$ sem. $2015 \cdot$ ORGANICOM \\ RÁDIO EDUCATIVA E MÍDIAS SOCIAIS DIGITAIS: PERSPECTIVAS E DESAFIOS DA FANPAGE DA RÁDIO UNESP FM}

Em relação ao número de curtidas por tema sobressaem: Música e Datas Especiais, por causa do aniversário da emissora. Depois aparecem as publicações sobre Eventos, Copa do Mundo, Cultura e Educação, Proteção Animal e Saúde. Com menos likesapareceram as publicações sobre Agência Propagação, Município, Segurança, Hortas Urbanas e Greve das Universidades, Trânsito e Meio Ambiente. Com duas curtidas, as publicações sobre Direito do Consumidor, Alistamento Militar e Golpe Militar. Já as postagens acerca de Diversidade, Mercado Imobiliário, Estágios e Empregos, Legislação, Campanha da Fraternidade, Marco Civil da Internet, Reformas em Habitação e Imposto de renda não obtiveram nenhuma curtida.

As curtidas nas publicações também são bons indicadores dos assuntos preferidos dos seguidores da fanpage de quanto os conteúdos divulgados atraíram ou não a atenção do público. Nesse ponto deve-se observar a linguagem das publicações e como esses conteúdos foram produzidos (se houve utilização de elementos que pudessem trazer mais informação e atrair mais a atenção da audiência, como imagens, vídeos, áudios e links complementares), bem como questões sobre planejamento, monitoramento e capacitação de pessoal responsável pela gestão de mídias sociais.

Gráfico 3 - Compartilhamentos por tema, de janeiro a junho de 2014.

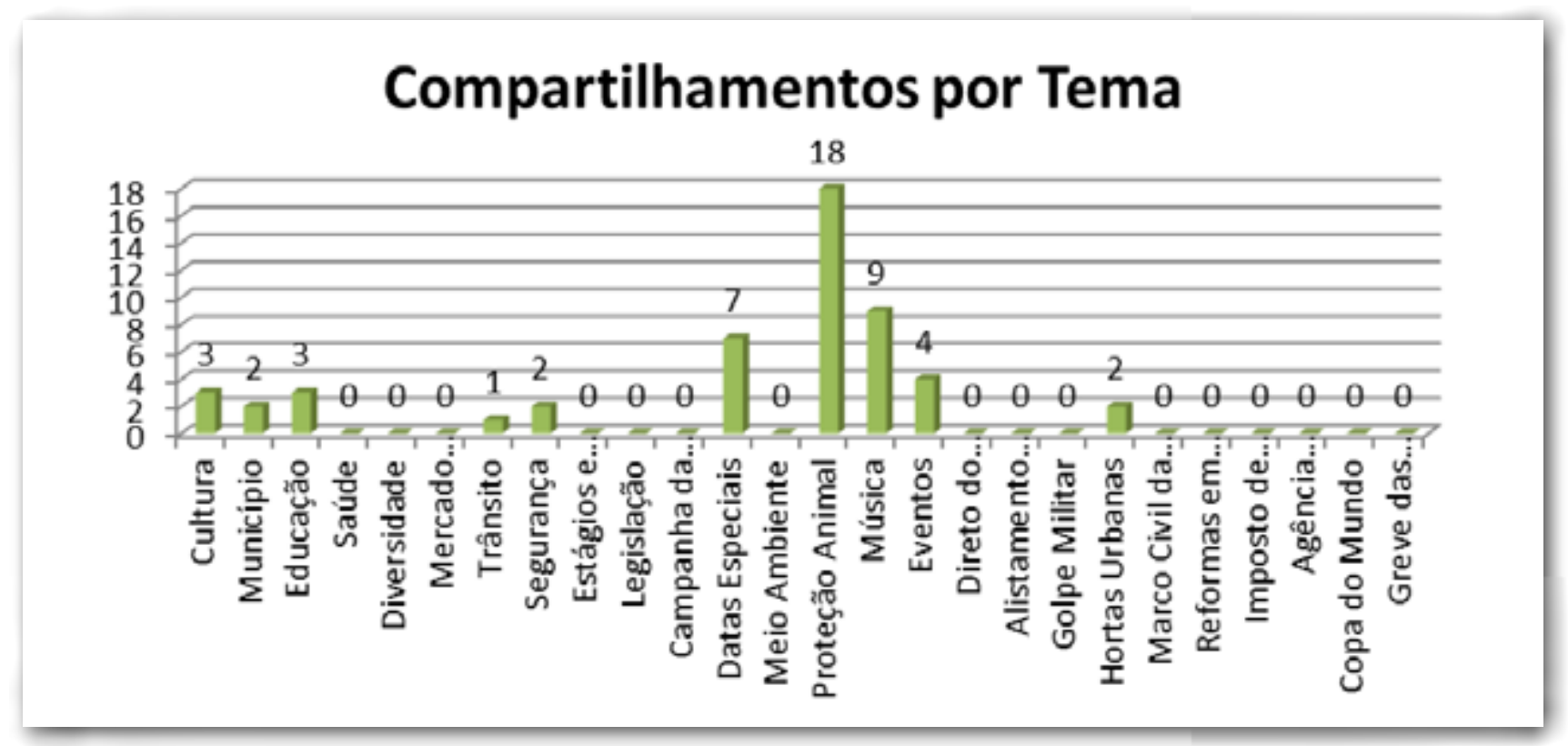

Fonte: Elaborado pelos autores.

Apesar de apresentar baixo nível de compartilhamentos, o tema mais compartilhado pelos usuários diz respeito à Proteção Animal, seguido pelas postagens que abordavam as temáticas Música e Datas Especiais. Em Datas Especiais o númeroalcançado relaciona-se às postagens sobre 0 aniversário da emissora, como foi apresentado nas análises mensais. As publicações que obtiveram menor nível de compartilhamentos foram sobre Eventos, Cultura, Educação, Município, Segurança e Hortas Urbanas e Trânsito. E Saúde, Diversidade, Mercado Imobiliário, Estágios e Empregos, Legislação, Campanha da Fraternidade, Meio Ambiente, Direito do Consumidor, Alistamento Militar, Golpe Militar, Marco Civil da Internet, Reformas em Habitação, Imposto de Renda, Agência Propagação, Copa do Mundo e Greve das Universidades não receberam indicações nenhuma vez.

Os compartilhamentos podem indicar o interesse dos usuários por temas específicos ou também a qualidade e relevância do conteúdo publicado, pois, quanto mais qualidade e relevância ele apresenta, mais abrangente se torna.

Dessa forma, é importante que sejam avaliados quais os assuntos de maior interesse das pessoas e produzir conteúdos relacionados a eles, e, quanto a assuntos menos compartilhados, planejar e desenvolver conteúdos mais atraentes, que despertem nos seguidores da fanpage a vontade de divulgá-los para seus amigos da rede. Outra ação simples é colocar no texto da publicação convites ao usuário para compartilhar os conteúdos a fim de ampliar sua visibilidade e seu alcance. 


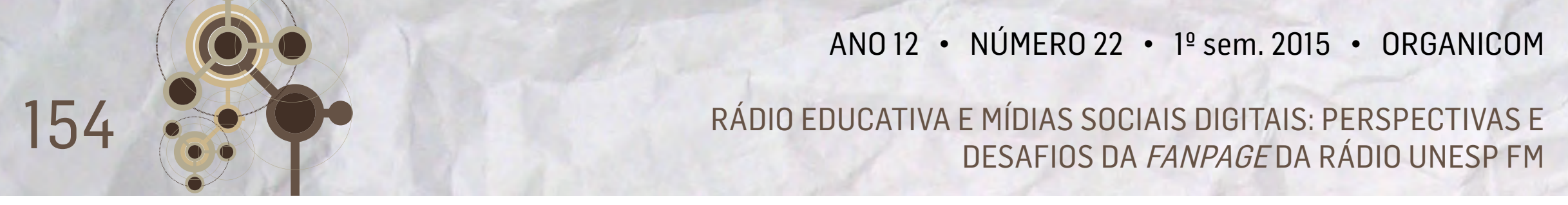

Gráfico 4-Comentários por tema, de janeiro a junho de 2014.

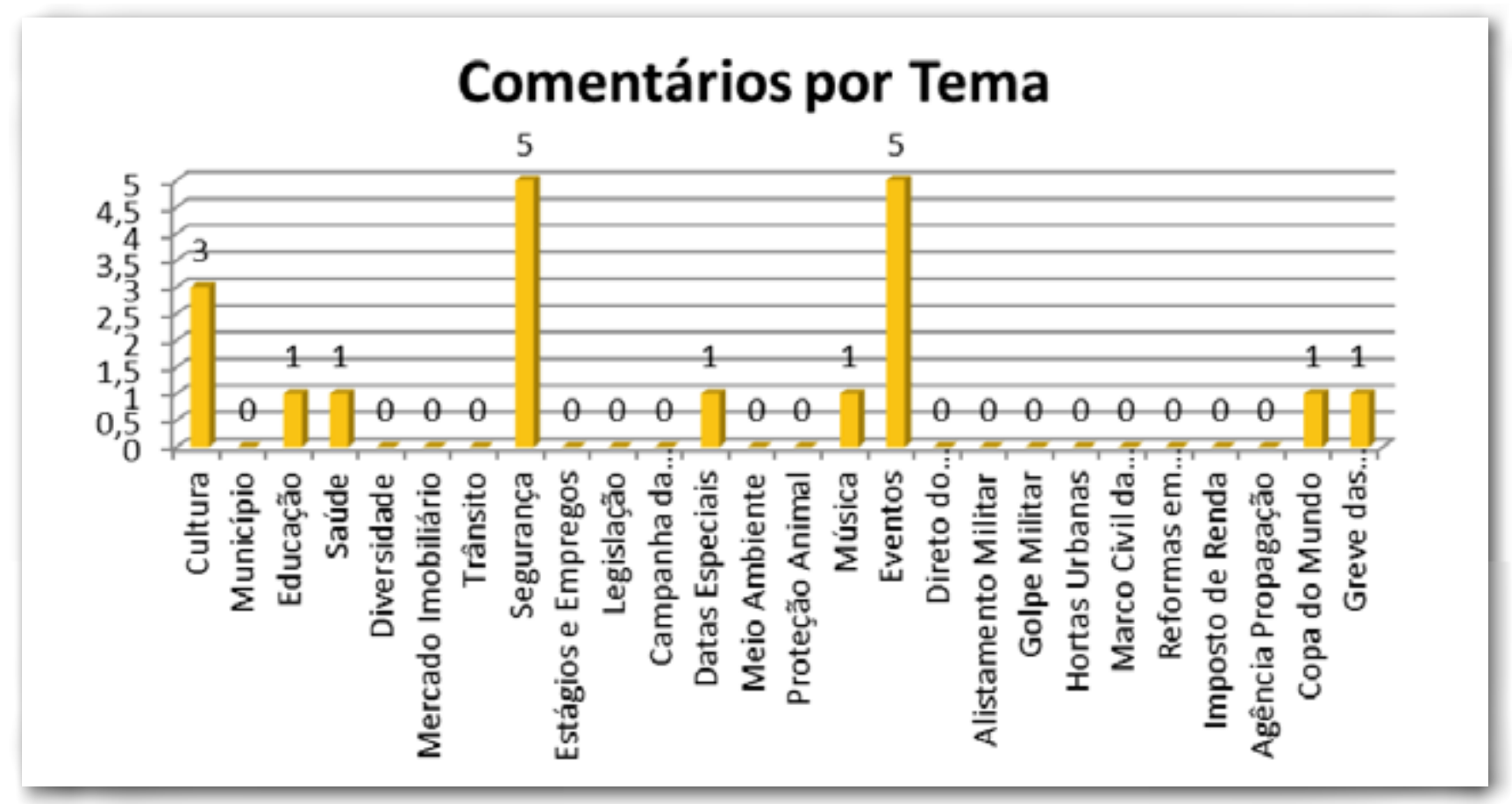

Fonte: Elaborado pelos autores.

O número de comentários, tal como dito anteriormente, é muito pequeno, indicando baixo interesse dos seguidores da fanpage em exporem suas opiniões sobre os temas abordados. Obtiveram comentários os seguintes tópicos: Segurança e Eventos (com 5 comentários cada), lembrando que para os dois itens surgiram comentários negativos acerca dos entrevistados e da abordagem da emissora sobre o assunto. Cultura teve 3 comentários e Educação, Saúde, Datas Especiais, Música, Copa do Mundo e Greve das Universidades obtiveram 1 comentário cada.

Esses resultados apenas reforçam a necessidade de planejamento e produção de conteúdos mais atraentes para os seguidores da fanpage e, como foi exposto anteriormente, criar algumas formas de auxiliar no aumento de interação desses usuários e, no próprio texto da publicação, como convidar os leitores a comentar, perguntar sua opinião e produzir conteúdos interativos como enquetes e pesquisas rápidas.

Gráfico 5 - Alcance médio por tema, de janeiro a junho de 2014.

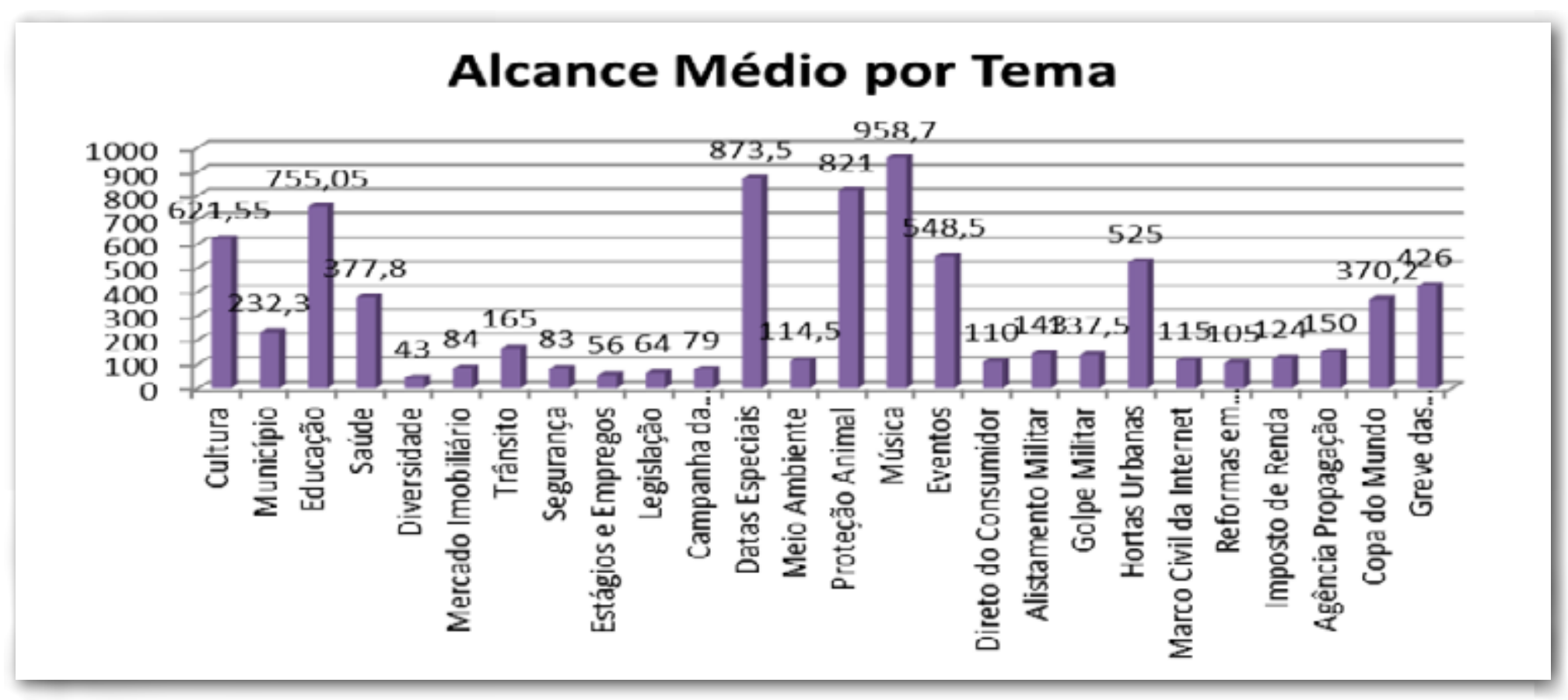

Fonte: Elaborado pelos autores. 
Agrupando as publicações por temas, as que obtiveram maior alcance foram as relacionadas a Música, Datas Especiais, Proteção Animal e Educação, seguidas por Cultura, Eventos, Hortas Urbanas e Greve das Universidades. Depois aparecem as temáticas Saúde, Copa do Mundo, Município, Trânsito, Agência Propagação, Alistamento Militar e Golpe Militar. E as de menor alcance foram Marco Civil da Internet, Meio Ambiente, Direito do Consumidor e, por último, Reformas em Habitação, Diversidade, Segurança, Campanha da Fraternidade, Legislação, Estágios e Empregos e Diversidade.

Esse item está relacionado a fatores como total de seguidores da página e também às ações dos usuários nas publicações como curtir, comentar e compartilhar. Também são indicadores dos principais interesses da audiência e da qualidade do conteúdo das publicações em relação a cada temática abordada.

Aumentar o alcance das publicações requer torná-las mais atraentes às interações dos seguidores da fanpage. Por isso, a necessidade de planejamento, gestão de conteúdo e profissionais capacitados para elencar quais assuntos serão abordados nas publicações e como esses materiais serão produzidos.

Gráfico 6 - Números totais de postagens, curtidas, compartilhamentos, comentários e alcance médio.

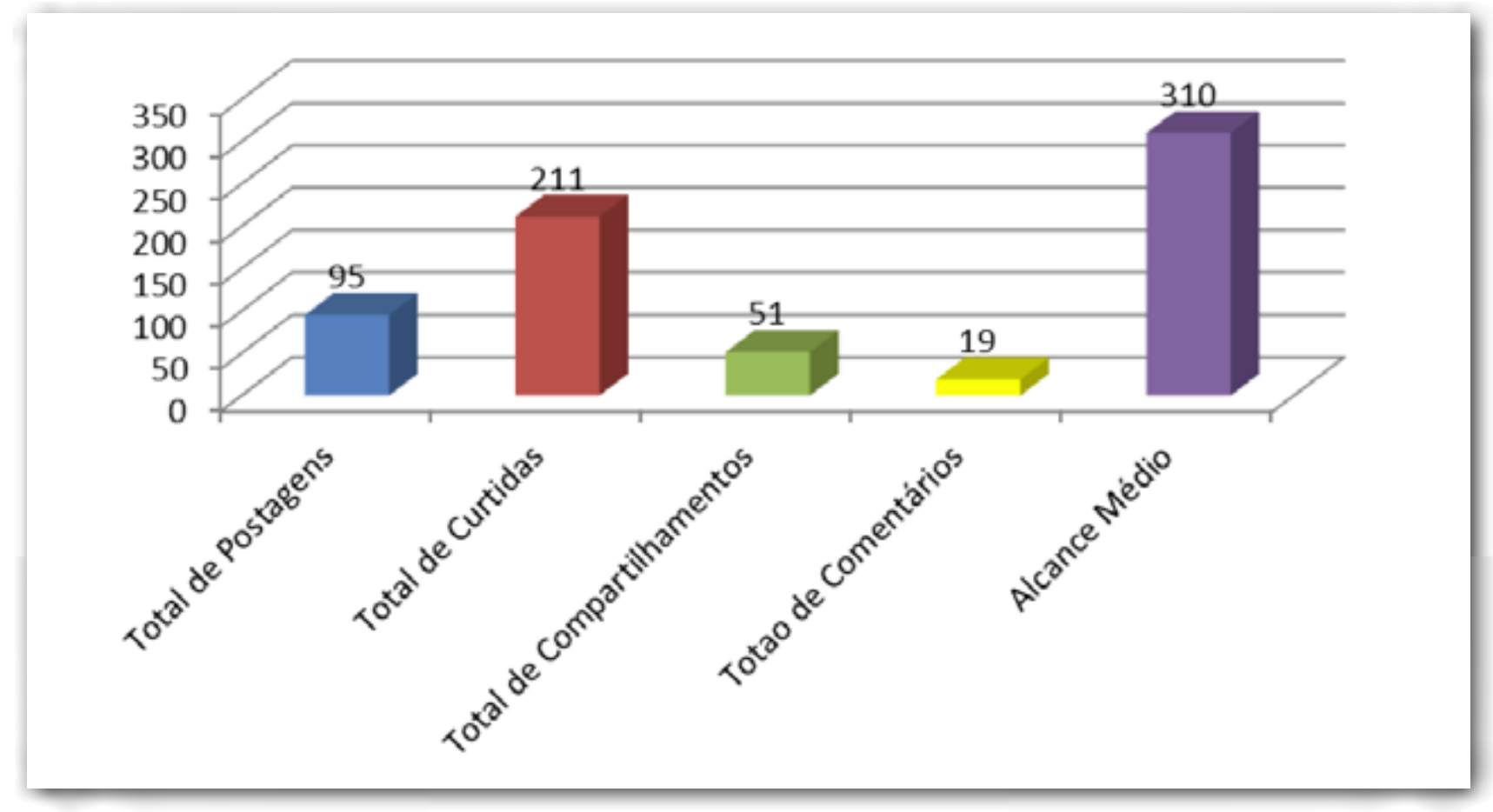

Fonte: Elaborado pelos autores.

Durante o período considerado nas análises (6 meses, de janeiro a junho de 2014) ocorreram 95 postagens, 211 curtidas, 51 compartilhamentos e apenas 9 comentários.

O volume de postagens da Rádio Unesp FM pode ser considerado muito baixo se levarmos em conta a diversidade de suas produções, pois em seis meses avaliados, uma expectativa de postagens diárias deveria ser de, no mínimo, duas postagens diárias, e o real número de postagens (95) é praticamente menos da metade disso. Esse baixo número de publicações devese, em parte, ao descaso da emissora com a realidade trazida pelas novas tecnologias que promovem a interatividade, pois não há sequer uma equipe ou funcionário destinados a tomar conta da fanpage e torná-la atrativa para seus públicos.

Nos três primeiros meses de análise ocorria o acúmulo de função em relação ao setor de jornalismo, que por não ser habituado ou treinado para a produção de conteúdo para mídias sociais digitais, apenas replicava o conteúdo na fanpage. Já 
nos três últimos meses de avaliação, havia a figura do bolsista vinculado a um projeto de extensão universitária, porém suas atividades não eram acompanhadas pela diretoria da emissora ou por algum professor responsável, não sendo necessário para o bolsista atingir metas ou apresentar resultados.

Em relação a curtidas, compartilhamentos e comentários, se observam números preocupantes devido à baixa interação dos usuários com os conteúdos publicados da fanpage.

0 alcance médio também tem que ser considerado baixo, atingindo aproximadamente $30 \%$ dos usuários da fanpage, quando na verdade números significativos de alcance médio vão além do total dos seguidores, pois se espera que os mesmos compartilhem os conteúdos para outras pessoas que ainda não fazem parte do grupo que já curtiu a fanpage.

Visto isso, são necessárias melhorias em relação à qualidade e periodicidade das publicações, a fim de conseguir resultados mais elevados de curtidas, compartilhamentos e comentários por parte da audiência da fanpage, ampliando o impacto de suas produções.

Gráfico 7 - Responsáveis pelas publicações, de janeiro a junho de 2014.

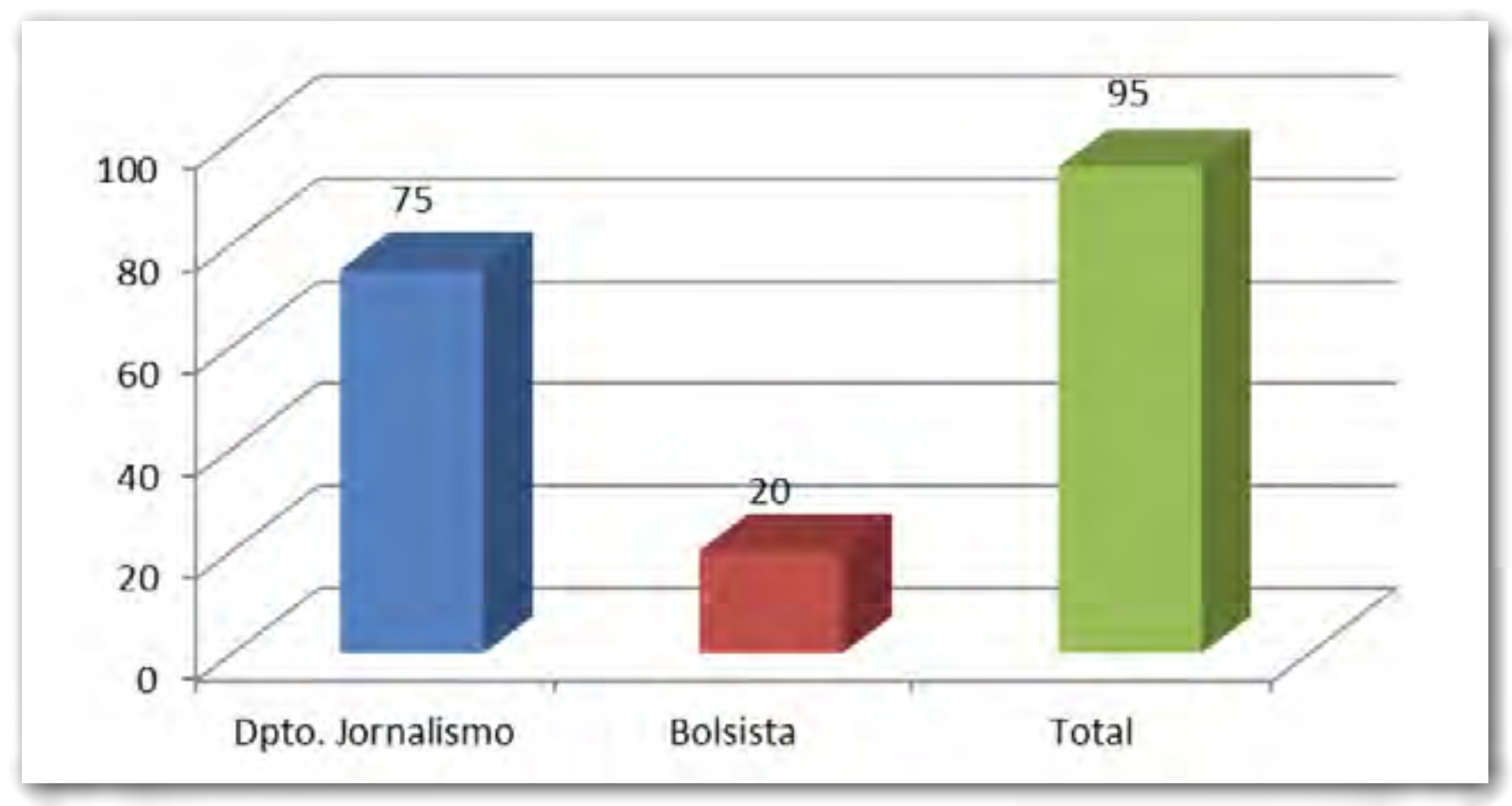

Fonte: Elaborado pelos autores.

Sabe-se que de janeiro a março, apenas o departamento de jornalismo realizava as postagens na fanpage, por causa da falta de pessoal para substituir o responsável anterior, ocorrendo o acúmulo de função. Nesse período de aproximadamente 90 dias, aconteceram 75 publicações (menos de uma por dia).

A partir do mês de abril, foi contratado um bolsista para auxiliar na produção de conteúdo e gerenciamento da fanpage, porém, como se pode notar através do gráfico, durante os três meses de atuação do bolsista, o mesmo realizou, apenas, 20 publicações. De acordo com o afirmado na entrevista, ele produzia 2 postagens por dia, o que resultaria em por volta de 120 postagem, considerando apenas dias úteis. Como se pode observar, essa fala não condiz com a realidade e denota falta de comprometimento e seriedade em relação às atividades relativas ao auxílio da bolsa, proveniente de recursos públicos, bem como falta de acompanhamento por parte da emissora ou do docente responsável pelo projeto.

Esses números demonstram a ineficiência da equipe de trabalho em relação ao planejamento e à gestão em mídias sociais, seja por questões de infraestrutura, acúmulo de trabalho ou falta de critérios na seleção do bolsista. 
As falhas ocorridas nesse ponto equivalem ao apresentado no livro Marketing de conteúdo: primeiros passos como gerar mais negócios através da geração de conteúdo (Rockcontent, 2014, p. 11). Foram elas: designar a função para jornalistas profissionais, mas que não têm experiência em conteúdo para internet; contratar um estagiário com pouco conhecimento sobre gestão de mídias digitais; e não investir em conteúdo de qualidade.

Em entrevista concedida pela diretoria da emissora, afirmou-se não haver nenhum tipo de capacitação nesse sentido, e que o bolsista não tinha nenhum conhecimento específico na área. Questões como baixa quantidade de conteúdo na fanpage e a falta de periodicidade nas postagens também foram apontadas em entrevistas realizadas com os funcionários da rádio.

Esses fatores, como a falta de equipe qualificada e capacitação para os colaboradores, geram falhas na produção do conteúdo, que, como evidenciado diversas vezes neste trabalho, é uma das peças chaves para o a comunicação em mídias sociais digitais.

Gráfico 8 - Interações respondidas e não respondidas, de janeiro a junho de 2014.

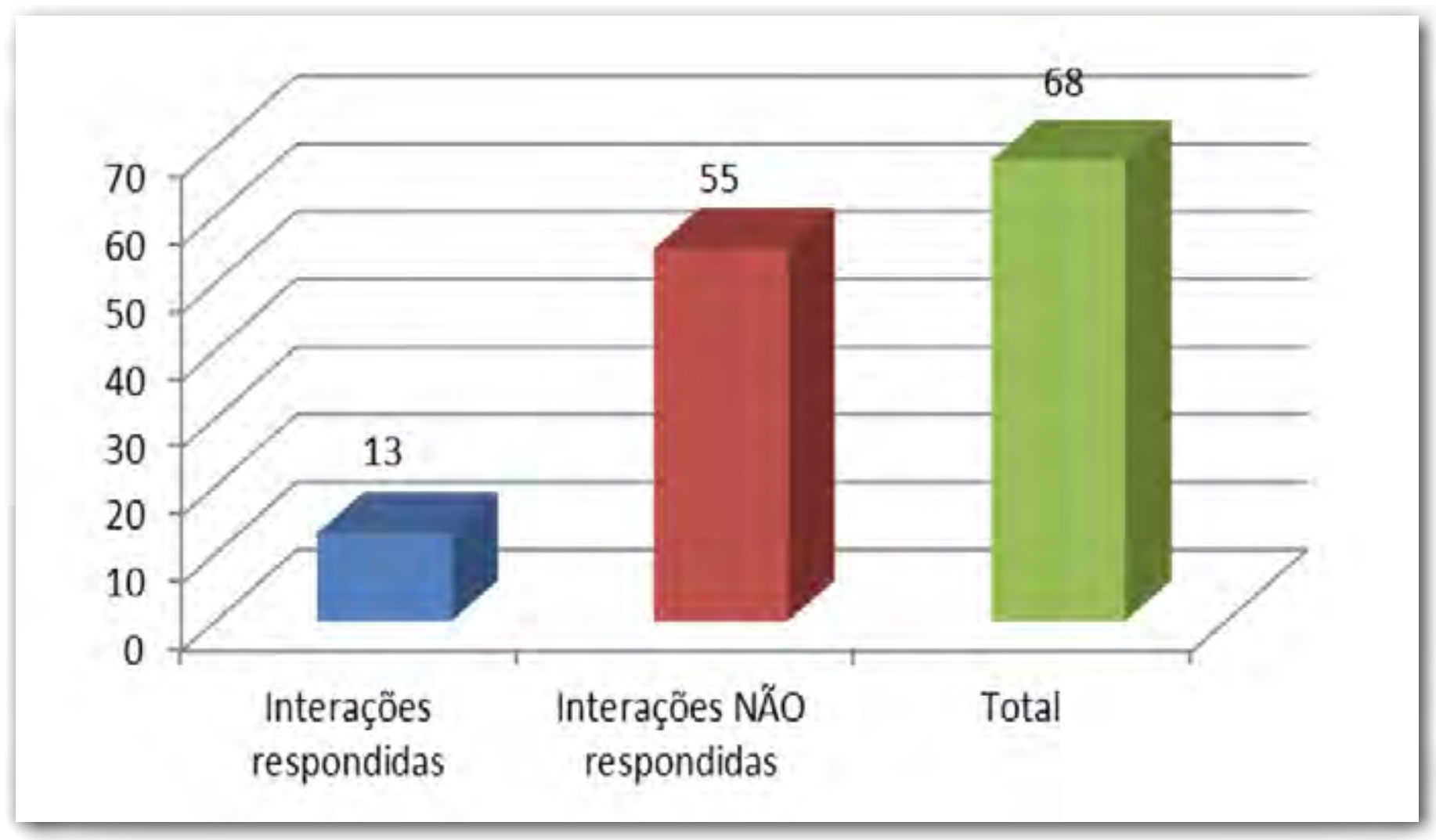

Fonte: Elaborado pelos autores.

No período de avaliação, houve a ocorrência de 68 interações diretas na fanpage da Rádio Unesp, das quais 55 ficaram sem resposta, e apenas 13 tiveram algum tipo de feedback por parte da moderação, o que indica graves falhas na realização do diálogo com os ouvintes.

Como é apontado por Carolina Terra (2008), conteúdos e interações gerados pela audiência não podem ser ignorados pelas organizações na era da transparência e da participação do cidadão-usuário.

Além disso, essa falta de feedback passa a impressão de que a rádio não se importa com seu público e não dá valor à sua audiência e opinião, o que pode gerar quebra de confiança e também minar as possibilidades de se estabelecer uma relação de fidelidade com esses públicos, num sentido contrário à lógica das mídias sociais, que é a de interatividade, diálogo, engajamento e construção coletiva de conteúdos e sentidos. 
Gráfico 9 - Conteúdo das interações, de janeiro a junho de 2014.

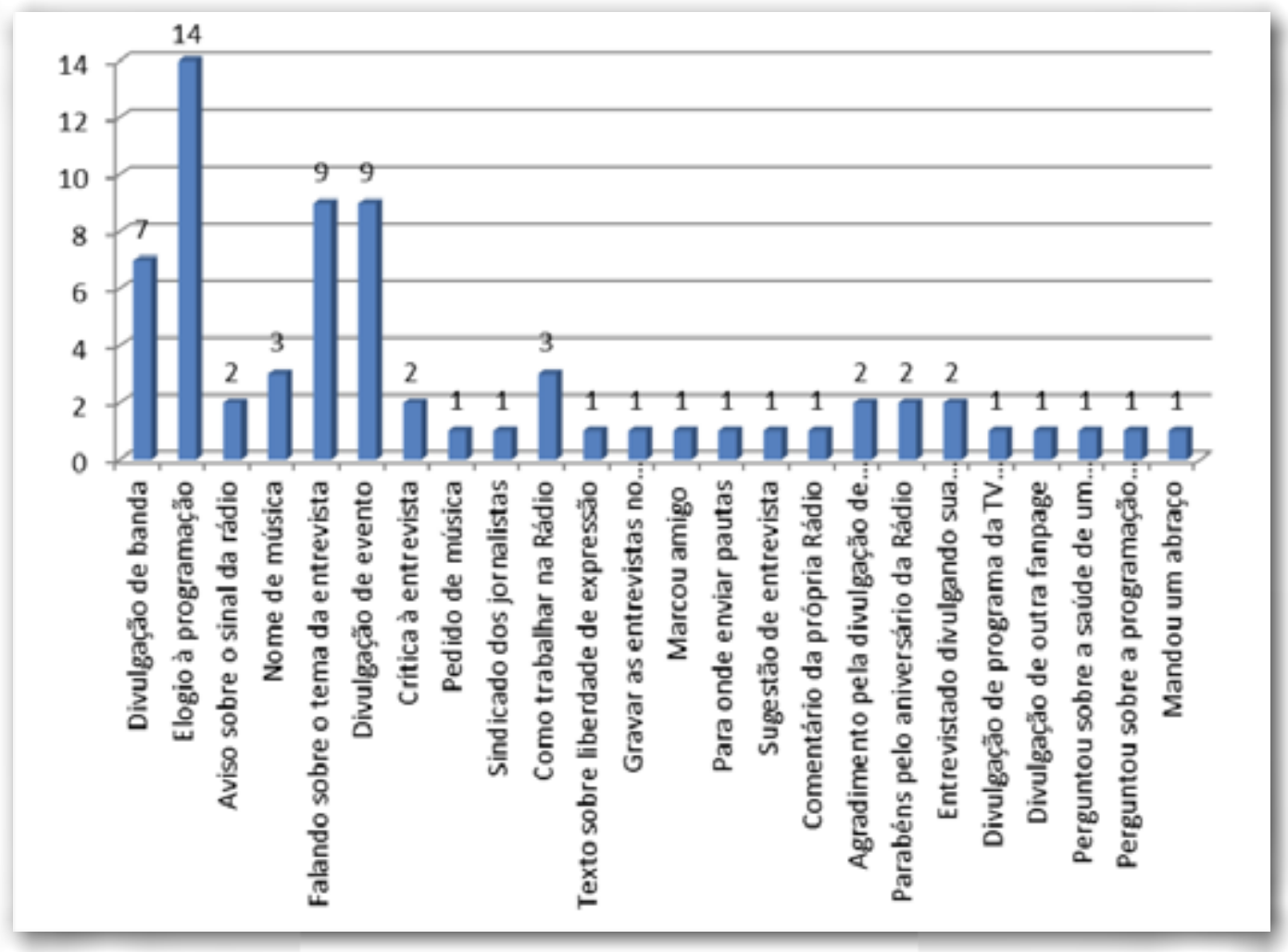

Fonte: Elaborado pelos autores.

No que se refere ao conteúdo das interações ocorridas, a maioria delas tratava de elogios à programação da rádio, comentários sobre a Entrevista do Dia, pedidos de Divulgação de Eventos e pedidos de Divulgação de Banda/Artista. Outras diziam respeito a perguntas de Nome de Músicas que foram tocadas na programação da emissora, pessoas querendo saber como faz para trabalhar na Rádio Unesp, ouvintes avisando sobre o Sinal da Rádio, Críticas aos entrevistados ou à abordagem da emissora sobre algum tema específico, Agradecimento pela divulgação de eventos, pessoas mandando parabéns pelo Aniversário da Rádio; e os próprios entrevistados Divulgando suas Entrevistas na Emissora.

As demais interações foram: Pedidos de Música; menção em texto sobre Liberdade de Expressão; outra menção em texto sobre o Sindicato dos Jornalistas; algum usuário que marcou seu amigo em uma das publicações; ouvinte perguntando para onde enviar sugestão de pautas; uma sugestão de entrevistado a ser convidado pela rádio; pedido de divulgação de uma outra fanpage; divulgação do programa Artefato da TV Unesp; uma pergunta sobre a programação; ouvinte perguntando sobre a saúde de um dos locutores, e também um ouvinte mandando um "boa tarde" para o pessoal da rádio.

Aqui pode ser apontada a questão do perfil participativo da audiência, pois

o rádio não fala mais para um ouvinte passivo, mas para alguém que deseja participar, contribuir - mais do que fazia até então. 0 ouvinte - agora também internauta - busca outras fontes de informação, cruza, contesta, discute, corrige, atualiza, conversa com o jornalista que está no ar. Mais do que nunca, o ouvinte participa (Lopez, 2010, p. 115).

Contudo, o número de interações é considerado baixo, tanto pelo conteúdo pouco atrativo como pela falta de feedback apresentada pelos moderadores da fanpage, que quebra o diálogo com o público e gera apatia, falta de vontade em realizar novas interações.

0 ideal aqui seria que todas as interações fossem atendidas, mesmo se a pessoa que está respondendo não souber responder exatamente à pergunta do ouvinte, mas pelo menos indicar outro setor que possa sanar a dúvida, ou dizer que irá buscar a informação e retornar depois. 


\section{ANO 12 • NÚMERO $22 \cdot 1^{10}$ sem. 2015 - ORGANICOM \\ RÁDIO EDUCATIVA E MÍDIAS SOCIAIS DIGITAIS: PERSPECTIVAS E DESAFIOS DA FANPAGE DA RÁDIO UNESP FM}

Se a interação for apenas um elogio, agradecer o ouvinte pela preferência; se ele pediu uma divulgação, dizer que o material será avaliado; se pediu uma música, agradecer pela sugestão e anunciar que em breve ela será tocada na programação da rádio; enfim, responder tudo, mesmo que seja apenas um "bom dia". É essa manutenção de diálogos que estimula o engajamento e a participação da audiência e, consequentemente, a visibilidade e o alcance da fanpage e dos conteúdos da Rádio Unesp.

\section{CONSIDERAÇÕES FINAIS}

Como rádio pública e educativa, a programação da Rádio Unesp FM é diferenciada e apresenta conteúdos que privilegiam a diversidade cultural, a música brasileira, questões pertinentes à cidadania, cultura e prestação de serviços. Considera-se, assim, sua inserção nas mídias sociais digitais ação essencial para sua divulgação e ampliação da visibilidade e do impacto de seus conteúdos na sociedade, tendo a fanpage como esse canal de comunicação.

A partir das análises realizadas, é possível notar uma presença incipiente da emissora no ambiente das mídias sociais, pois, nesse espaço promotor de relacionamento com a audiência e no qual ocorrem os processos de convergência e interatividade, não basta apenas estar presente, sendo preciso estar realmente ativo e receptivo às interações do ciberouvinte.

Nota-se a necessidade de buscar o engajamento da audiência, pois, se a emissora precisa de visibilidade e repercussão, o melhor a fazer é criar um conteúdo relevante para seus públicos e situações que estimulem a participação. Utilizar as mídias sociais apenas para replicar as atividades da emissora não basta, sendo necessária sua integração na lógica da convergência, integrando conteúdos e pensando as práticas comunicacionais voltadas para uma audiência dispersa, multiplataforma, ultraconectada, que quer interagir, dar sua opinião e produzir conteúdos.

Foram encontrados problemas, de fato, em relação à seleção e capacitação da equipe de trabalho, na adequação dos conteúdos e na falta de feedback aos usuários da fanpage, mas tais problemas devem ser sanados gradativamente, à medida que a emissora incorporar em suas práticas a compreensão de como seus conteúdos podem ser incorporados nesse ambiente e como dialogar com a audiência.

Novas perspectivas são abertas para a Rádio Unesp FM ao levar em conta o potencial expansivo e colaborativo das mídias sociais, pois um canal interativo como a fanpage (caso bem trabalhada), somada ao novo perfil do ouvinte-internauta, pode trazer contribuições significativas para suas produções e também para ampliação do alcance de seus conteúdos.

Por fim, espera-se que o estudo sirva de apoio não apenas à Rádio Unesp FM, mas também a outras rádios educativas e a veículos de comunicação pública, que, ao buscarem sua inserção nas mídias sociais, possam ter parâmetros para realizar essa tarefa de maneira adequada e eficaz, a fim de levar à maior quantidade possível de pessoas conteúdos caros à educação, cultura, informação e cidadania, para o cumprimento de sua função social.

\section{REFERÊNCIAS}

ANDRELO, Roseane; KERBAUY, Maria Teresa. Gênero educativo no rádio: parâmetros para a elaboração de programas voltados à educação. Intercom - Revista Brasileira de Ciências da Comunicação. São Paulo, v. 32, n. 2, p. 147-164, jul./dez. 2009. 
BLOIS, Marlene. Rádio educativo no Brasil: uma história em construção. In: CONGRESSO BRASILEIRO DE CIÊNCIAS DA COMUNICAÇÃO, XXVI, Belo Horizonte, Intercom, 2 a 6 de setembro de 2003. Disponível em: <http://www.portcom.intercom. org.br/pdfs/125264023715941274770374088408981912085.pdf>. Acesso em: 17 jan. 2015.

BUENO, Wilson da Costa. Comunicação empresarial: teoria e pesquisa. São Paulo: Manole, 2003.

CEBRIÁN HERREROS, Mariano. 0 rádio no contexto da comunicação multiplataforma. Rádio-Leituras, Santa Maria, RS, v. 2 , n. 2, p. 69-105, jul./dez. 2011.

CORDEIRO, Paula. Rádio e internet: novas perspectivas para um velho meio. II In: CONGRESSO IBÉRICO DE COMUNICAÇÃO, II, Covilhã, Portugal, 2004.

Disponível em: <http://bocc.ubi.pt/pag/_texto.php3?html2=cordeiro-paula-radio-internet-novas-perspectivas.html>. Acesso em:12 abr. 2014.

CORNACHIONE, Daniella. As empresas querem entrar. Época, São Paulo, n. 628, p. 92-94, 31 mai. 2010.

FERRARETTO, Luiz Artur. Rádio: o veículo, a história e a técnica. Porto Alegre: Editora Sagra Luzzatto, 2001.

IVO, Diego. Guia de redes sociais para empresas: Twitter, Facebook, Ormspring e blogs. Primeiro Lugar, São Paulo, 7 abr. 2010. Disponível em: <http://www.primeirolugar.net/blog/redes-sociaispeq-medias-empresas.html>. Acesso em: 17 jul. 2014.

LEITE, Wellington César Martins. A representação do caipira na Unesp FM. 2013. 335 p. Dissertação (Mestrado em Comunicação) - Faculdade de Arquitetura, Artes e Comunicação, Unesp-Bauru, Bauru, 2013.

LOPEZ, Debora Cristina. Radiojornalismo hipermidiático: tendências e perspectivas do jornalismo de rádio all news brasileiro em um contexto de convergência tecnológica. Covilhã: LabCom, Portugal, 2010. Diponível em: <http://www.livroslabcom. ubi.pt/pdfs/20110415-debora_lopez_radiojornalismo.pdf>. Acesso em: 14 dez. 2014.

LOPEZ, Debora Cristina; QUADROS, Miriam Redin de. Rádios e redes sociais: novas ferramentas para velhos usos? Intexto, Porto Alegre, UFRGS, n. 30, p. 166-183, jul. 2014.

OLIVEIRA, Aline Meneguini de. Interação comunitária: o cidadão em sintonia radiofônica. 2013. 245 f. Dissertação (Mestrado em Comunicação) - Faculdade de Arquitetura, Artes e Comunicação, Unesp-Bauru, Bauru, 2013.

ROCKCONTENT. Marketing de conteúdo: primeiros passos como gerar mais negócios através da geração de conteúdo. E-book. 2014. Disponível em: <http://materiais. rockcontent.com/ebook-marketing-conteudo-primeiros-passos>. Acesso em: 02 jan. 2015.

ROLDÃO, Ivete Cardoso do Carmo. O rádio educativo no Brasil: uma reflexão sobre suas possibilidades e desafios. In:CONGRESSO BRASILEIRO DE CIÊNCIAS DA COMUNICAÇÃO, XXIX, Brasília, 6 a 9 de setembro de de 2006. Anais... São Paulo: Intercom, 2006.

TERRA, Carolina Frazon. Blogs corporativos: modismo ou tendência? São Caetano do Sul, SP: Difusão, 2008.

VELHO, Ana Paula Machado. A linguagem do rádio multimídia. Biblioteca on-line de Ciências da Comunicação (Bocc), Covilhã, Portugal, LabCom, 2005. Disponível em: <http://www.bocc.uff.br/_listas/tematica.php?codtema=52>. Acesso em: 02 fev. 2014. 